Could Vegans and Lycra Cyclists be Bad for the Planet? Theorising the Role of Moralised Minority Practice Identities in Processes of Societal-level Change

Tim Kurz $^{1 *}$, Annayah M.B. Prosser ${ }^{1}$, Anna Rabinovich $^{2} \&$ Saffron O’Neill $^{3}$

${ }^{1}$ Department of Psychology, University of Bath, United Kingdom

${ }^{2}$ School of Psychology, University of Exeter, United Kingdom

${ }^{3}$ Geography, College of Life and Environmental Sciences, University of Exeter, United Kingdom

*Address for correspondence: Tim Kurz, Department of Psychology, University of Bath, Claverton Down, Bath, BA2 7AY, United Kingdom.t.kurz@bath.ac.uk 


\begin{abstract}
Shifting society to more sustainable modes of consumption poses significant challenges to the way people live their lives. Many everyday practices commensurate with addressing sustainability goals are currently minority pursuits, especially in highly industrialised countries. Such minority practices often come to form the basis of social identities (e.g., as 'vegans' or 'cyclists'). These moralised minority practice identities (MMPIs) represent the focus of this theoretical paper. We theorise the nature and genesis of MMPIs, discuss how their characteristics shape intergroup interactions and consider implications for societal-level change. We make the contentious suggestion that, contrary to what might be predicted on the basis of social identity approaches to social change, strong identification with 'green practice' groups may hamper, rather than facilitate, societal-level shifts towards sustainability. We discuss the need for policy approaches that enable people to experiment with new sustainable practices without the pressure to commit to a particular practice identity.
\end{abstract}

Keywords: Social Identity; Moral; Meat; Cycling; Zero-waste; Flight shame 


\section{Could Vegans and Lycra Cyclists be Bad for the Planet? Theorising the Role of Moralised Minority Practice Identities in Processes of Societal-level Change}

Almost all of the activities people participate in on a daily basis have implications for our collective ability to achieve environmental sustainability, that is, to meet our current needs without compromising the ability of future generations to meet theirs (Brundtland, 1987). Practices of everyday dietary sustenance (Ginn \& Lickel, in press), mobility (Chng, in press) and material consumption (Dennings, in press; Saber \& Silka, in press), and the interrelationships between them (Dreyer et al., in press), have a significant impact on our progress towards achieving a variety of environmental objectives, including lowering greenhouse gas emissions, improving air quality and reducing ground and water consumption and contamination. However, despite the relative mainstreaming of attitudinal concern about such matters within many modern industrialised nations (Capstick et al., 2014; Dunlap \& Mertig, 2013), the kinds of practices that might lead to more environmentally sustainable outcomes remain minority pursuits in many contexts. For example, plant-based diets and cycling to work are activities engaged in by only a small fraction of the population in many industrialised nations (less than 5\% in both cases in the UK/USA), despite them being promoted at various levels of governance as having environmental - as well as other personal and collective - benefits (Department for Transport, 2017; Wellesley, Happer \& Froggatt, 2015). For those engaging in these minority practices, this often constitutes more than merely an 'activity'. Such practices can form part of individuals' sense of identity and group membership, for example, as 'vegetarians'/‘vegans'(i.e., veg*ans) (Rosenfeld \& Burrow, 2017), 'cyclists' (Aldred, 2013; Hoekstra, Twisk \& Hagenzieker, 2018), 'voluntary simplifiers' (Lorenzen, 2018) or 'zero wasters' (Clark, 2016). These identities formed around environmentally consequential, potentially-moralised, minority practices represent our current focus. We term them "moralised minority practice identities" (or MMPIs) and argue 
that their understanding plays an important role in explaining and predicting environmentally sustainable behaviour (and responses to it).

\section{The Genesis and Nature of MMPIs}

We first outline the key theoretical elements of MMPIs that render them a distinct and important object of social psychological enquiry that has particular relevance for the promotion of environmentally sustainable practices across society.

\section{From Practice to Social Identity}

In what sense can one describe a minority of people who participate in (or avoid) a particular practice as having a shared social identity, or as being part of a 'group'? Our answer to this question has its roots in the social identity theory account of what constitutes 'a group' with which one can socially identify, as originally formulated by Tajfel (1978). Tajfel argued that being part of a group includes a) having the cognitive knowledge that one belongs to the group, b) membership of the group having positive or negative value connotations, and c) the cognitive and evaluative aspects of the group leading to emotions directed towards one's own group and towards those who are positioned in oppositional relation to it.

We posit that minority dietary, transport, and waste identities can be argued to exhibit precisely these properties. Those who intentionally follow plant-based diets, regularly choose to cycle over driving, or follow zero-waste principles are highly likely to have knowledge of themselves as being socially locatable as veg*ans, cyclists and zero-wasters, and that they share this social group membership with others who engage in similar practices. Examples of sizeable Facebook groups such as 'London Cyclists', 'UK Vegan' and 'Zero Waste Heroes' provide testimony to this effect. This is not to say that individual practitioners do not vary in their level of identification (Cameron, 2004) with the practice-based groups in question. However, this is true of all social identities - those who are members of the gender groups of 
'men' and 'women' vary in how strongly they identify with that group, but this does not undermine the significance of their membership in terms of how they are socially categorised in social life.

We do not assume that to engage in a sustainable practice is necessarily to internally or cognitively adopt the MMPI based around it. However, what we are suggesting is that one's behaviour can (and indeed often is) read by others as a sign of performing a particular identity. While it is certainly possible for one to participate in a practice while avoiding claiming an associated identity, in many contexts, social and structural arrangements make that difficult. For example, although one could abstain from animal products while not wanting to necessarily be socially categorised in terms of the social identity of 'Vegan', in many shared eating contexts this is practically difficult to do. The social world often involves a risk that others read us as members of social groups, regardless of whether we see ourselves as such. Moreover, self-verification theory (Swann, 2011) posits that such experiences of being mis-read are something people are highly motivated to avoid. If one does not wish to be seen as 'A Vegan' (and all that this may entail for others), then adopting practices that define this social category in others' minds is obviously risky social psychological business.

In relation to Tajfel's (1978) further two group properties, examples such as cyclists and veg*ans provide ample evidence that these group memberships have certain positive/negative connotations in the minds of both group members and others, and of their ability to colour emotional responses to in/outgroup members. For instance, Aldred (2013) demonstrated cyclists' need to carefully manage the potential stigma from motorists associated with their social identities. Moreover, Hoekstra, Twisk and Hagenzieker (2018) recently demonstrated that those who self-identified as 'cyclists' felt they had more in common with 'cyclists' than with 'car drivers', with the reverse true among those identifying as 'car drivers'. Furthermore, these intergroup perceptions were shown to influence the 
likelihood of yielding to someone on the road. Examinations of in/outgroup identity processes in the dietary domain have become increasingly common, both from the perspective of the meat-eating majority's responses to veg*ans (e.g., MacInnis \& Hodson, 2017; Minson \& Monin, 2012) and also how veg*ans manage their stigmatised identities in interactions with the majority outgroup (e.g., Greenebaum, 2012; Romo \& Donavan-Kicken, 2012; Twine, 2014). Thus, membership in MMPI groups has an evaluative component (often with behavioural consequences) for both those who belong to them and for outgroup observers.

\section{The Moral Nature of Moralised Minority Practice Identities (MMPIs)}

A key characteristic of MMPIs is that the practices they form around possess a high potential to be construed in moral terms. This potential does not rest on an assumption that those engaging in the practice are internally motivated by moral reasons. Rather, what is crucial is that their practices may be read in moral terms by others. For example, Minson and Monin (2012), showed that negative reactions exhibited by the meat-eating majority towards vegetarians (as a group) were driven by meat-eaters feeling collectively morally judged by members of the MMP group for their failure to avoid meat, regardless of any direct evidence of the MMP group's judgement. Bolderdijk, Brouwer, and Cornelissen (2018) demonstrated a similar effect in the context of zero-wasters, showing that reactions of derogation (rather than inspiration) were particularly evident when the behaviour of 'do-gooders' could be interpreted as a threat to onlookers' moral self-concept.

We posit that participation in putatively pro-environmental practices by a minority is almost unavoidably construable by the non-practicing majority in ways that threaten their moral self-concept, at least where participation is seen as a voluntary choice, and where there exists a general social norm that construes environmentally sustainable behaviour as desirable. A prime recent example is the Flygskam ('Flight Shame') movement spreading 
from Sweden across parts of northern Europe in 2019, popularised by teenage activist Greta Thunberg (Coffey, 2019). Adherents, who often identify themselves with hashtags like \#jagstannarpåmarken ('I stay on the ground'), eschew air travel and engage in Tågskry ('train brag') by positing pictures of their non-flight journeys on social media (West-Knights, 2019). Such posts have not been without their detractors however, such as British businessman and political donor Aaron Banks whose high-profile response to a tweet depicting Thunberg setting sail on a yacht to the UN suggested that "Freak yachting accidents do happen in August" (Busby, 2019). We suggest that similar kinds of processes may also come into play in relation to other sustainable practices. For example, at least some component of the aggression sometimes directed towards cyclists by motorists in Britain (Fruhen \& Flin, 2015) likely stems, we would argue, from a perception that cyclists morally judge them in some way for travelling by car. Such reactions may be likely to increase as a function of stronger injunctive norms against car travel in city centres following the current launch of various Clean Air Zone initiatives across Britain (Cannon, 2019).

The moral rebel literature thoroughly highlights the kinds of cognitive processes of derogation engaged in by the 'less moral' majority towards moralised minorities (Cramwinckel, van Dijk, Scheepers \& van den Bos, 2013; Minson \& Monin, 2012; Monin, Sawyer \& Marquez, 2008). However, the primary target of our theoretical exploration here is how reactions to moral rebels pan out at the level of intergroup interaction, and the implications of this for societal-level change. We suggest that the importance of moral rebel effects at this level of analysis lies in their propensity to potentially a) reduce willingness of MMP group members to advocate for the practice in question (lest they experience majority derogation), and b) reduce the likely success of said group members in influencing/recruiting the majority when they are willing to try (as it may be easier for the majority to derogate rather than be stirred to change their practices). 


\section{MMPIs as Practice-based Rather than Opinion-based}

It is important to draw a clear theoretical distinction between the practice-based identities that represent our current focus and the idea of identities forming around opinionbased groups (OBGs) that has been previously developed in the social identity literature by McGarty and colleagues (McGarty, Bliuc, Thomas \& Bonjiorno, 2009; Bluic et al., 2015). OBGs refer to social groups and their associated identities that are defined by a principle (e.g., pro-lifers, feminists, climate skeptics, environmentalists). A key difference between these groups and our notion of practice-based identities is that for OBGs the behavioural manifestations of group membership are rather loosely defined. For example, those who identify with the opinion-based group 'Feminists' clearly share an opinion regarding the need to address gender inequality in society. Moreover, people who identify with this OBG may refrain from a set of potential behavioural practices (e.g., adoption of paternal last names within families, wearing (by women) of impractical footwear, or consumption of sexually objectifying media). However, the set of practices that 'feminists' refrain from performing can be best described as a 'fuzzy set' (Smithson \& Verkuilen, 2006), in the sense that failure to refrain from any particular practice does not cleanly and inarguably preclude someone from claiming membership in the OBG. The same can be said of the OBG of 'environmentalists'. While members of this OBG may tend towards favouring active or public transport over driving, refraining from consuming meat, and avoiding various forms of material consumerism, their participation in any one of these practices is not a strict requirement of their social or psychological inclusion in the group. In contrast, practice-based groups are defined by specific behaviours that all members of the group perform: Engaging with or refraining from this behaviour places one within or outside the group boundary. For example, someone cannot identify as 'a cyclist' if they never cycle, or as 'a vegetarian' while regularly consuming meat. 
We argue that the fact that membership in MMP groups is so tightly behaviourally defined has important implications for the psychological and interactional relationships between those who do and do not identify as members of the group in question (e.g., veg*ans and meat-eaters). Whereas, in contrast, people's identification with OBGs, such as a 'feminist' or 'environmentalist', can be much more flexible and fluid in the context of their social interaction with others, leaving open opportunities for both 'passing' as a member of an OBG and 'concealment' of one's membership in this group. For example, one can easily avoid being morally shamed as not a feminist or environmentalist on the grounds of one's conduct by virtue of the OBG being defined by a relatively fuzzy set of practices. Likewise, it is also easier for OBG members to avoid potential social interactional trouble caused by outing themselves during interaction with outgroup members than is the case for many practice-based identities. The inextricably social nature of the practices that typically define MMPIs makes it difficult to avoid 'identity flashpoints' (cf. Coulthard, 2009), in which one is forced to reveal one's identity and where there is potential for social awkwardness. For example, it may well be possible (albeit challenging) for someone to simply avoid talking about climate change or feminism with misogynist or climate sceptical family members at Christmas dinner. However, for someone who arrived to a family Christmas holiday as the only no-flyer, vegan, or voluntary simplifier, and, as such, arrived a day late, refused to eat the turkey or to engage in communal materialist gift-giving, the chances of avoiding socialinteractional trouble would be far slimmer (Lorenzen, 2018)! Therefore, the adoption of behaviourally-defined MMP identities become more socially consequential for potential new recruits than is the case for opinion-based identities such as 'environmentalist'.

\section{MMPIs as Identities (Often) Born Out of Marginalisation}

The inherently social nature of the practices around which many MMPIs are defined, together with their status as a minority pursuit within society, can result in marginalisation for 
MMP group members. One might postulate that strong MMPIs may often be forged from an experience of marginalisation and the associated identity threat. Examples include material safety threats for cyclists from other road users (Prati, Puchades \& Pietrantoni, 2017) and social interactional threats for veg*ans during group dining with meat-eaters (Twine, 2014). As suggested by the rejection-identification model (Branscombe, Schmitt \& Harvey, 1999; Jetten, Branscombe, Schmitt \& Spears, 2001), it is common for members of disadvantaged minority groups to respond to threats to their identity by strengthening identification with their minority group. Jetten et al. (2001) have shown that this process can indeed occur for identities that are defined by a specific practice, such as the wearing of body piercings. We would suggest that this process of strengthening ingroup identification by virtue of outgroup threat is rather chronic in the case of many MMPIs that relate to sustainability, as a result of interactions taking place at the many identity 'Flash points' described above. This, we would argue, is precisely why, for many, participation in the practice moves beyond merely 'something one does' to become part of 'who one is', with that sense of who one is being shared with other practitioners and thus constitutive of social identity.

\section{Social Identities and Social Change}

Social identity theory (SIT) perspectives on social change position strength of identification with one's minority group as a key variable in predicting people's motivation and willingness to engage in collective action in pursuit of social change (e.g., van Zomeren, Postmes \& Spears, 2008). On this basis, MMPIs should be a positive force towards more sustainable societal outcomes insomuch as they motivate their members to push for societylevel change. However, we suggest that this well-documented process of motivating collective action through identification with minority groups may produce quite different outcomes when applied to MMPIs. We propose a somewhat paradoxical process, whereby the more strongly identified current MMP group members are, and the more tightly defined 
the contents (and boundaries) of these identities become, the less able the MMP group is to recruit new practitioners and inspire societal-level change. While SIT models of identity encourage us to think of minority group identification as the process that empowers change, moving societies towards 'tipping points', we propose these minority identities forged around specific moralised practices may instead act as barriers ('sticking points') to societal change.

\section{Different Contexts of Social Change Require Different Models of Understanding}

SIT models of social change are focussed on understanding a societal dynamic in which certain groups have access to power, status, and resources, which allows them to confer unjust relative disadvantage upon groups that do not have access to this power, status and resources (Turner, Hogg, Oakes, Reicher \& Wetherell, 1987). Contexts such as African Americans fighting for racial equality via the civil rights movement or the suffragettes for gender equality represent prime examples of this dynamic. SIT argues that when strongly identified members of disadvantaged groups perceive group boundaries as impermeable (e.g., race/gender), and perceive their lower status as illegitimate, this fuels emotions such as moral outrage. This moral outrage, in turn, helps fuel motivations to band together with fellow group members and engage in collective action to attempt to arrest power and resources from the dominant outgroup (Ellemers, van Knippenberg \& Wilke, 1990).

This SIT model captures well processes of social change that exhibit this dynamic. However, some forms of social change are less well captured by these models, a point that has begun to be noted (but not fully theoretically/empirically explored) by researchers analysing the role of identities in social change. Wright (2009) makes the crucial distinction between the 'intergroup competition' (IGC) collective action context and a 'conversionary collective action' (CCA) context. He suggests that in IGC contexts the main concern is avoiding the out-migration of ingroup members away from supporting their group's common cause. Thus, ingroup (e.g., race/class/gender) solidarity here becomes a crucial factor of focus 
for both activists and the scholars who study their activities. Likewise, in an IGC context, the outgroup is most often represented as a villain and a target of anger. By contrast, the main aim in a CCA context becomes an in-migration of formerly outgroup members (i.e., conversion). The domain of environmental behaviour arguably represents the quintessential example of a CCA context. In order for social change to happen towards more sustainable diets and forms of transportation, meat-eaters and motorists need to become vegetarians and cyclists in a way that is not true of IGCs (the civil rights movement wasn't about making White people Black, nor were the suffragettes trying to convert men into women). This conversion process in a sustainability context is arguably hampered as a function of the strength of ingroup identification amongst the MMP group. Thus, while ingroup solidarity and moral conviction are crucial ingredients to social change in an intergroup conflict context, they represent potential barriers to openness to newly converted members in an identity conversion context. Strong identification with one's group works well for getting the ingroup rallying around an ingroup cause against a common enemy but may paradoxically hamper the group's capacity for conversionary action to bring others into the fold. If successful social change necessitates bringing others into the fold, then strong ingroup identification potentially represents a problem.

An appreciation of such tensions in other contexts has led theorists in these domains to highlight the potential importance of cross-group 'allies'. For example, gender researchers have highlighted the potential benefits of (female) feminists recruiting 'male allies' to the cause (Cihangir, Barreto \& Ellemers, 2014; Drury \& Kaiser, 2014; Subašić et al., 2018). In these contexts, the disadvantaged group aims to gain the ideological/symbolic support of members of the privileged (out)group. However, these intergroup contexts involve a different dynamic to sustainability contexts, such as dietary, mobility, and material consumption practices. Here, the notion of an 'out-group ally' becomes rather difficult and slippery, but 
perhaps not unimportant. For example, Aldred (2012) suggests the possibility that 'potential cyclists' might really be the primary constituency of concern for cycling advocates.

Similarly, in the dietary domain, Twine (2014) speaks of the potential importance of 'nonpracticing practitioners' (p. 632) of veg*anism - those supportive of such diets and who actively seek to accommodate followers' needs even though they eat meat/dairy themselves.

The importance of such 'allies' in this context may lie in their willingness to advocate for the provision of practice-facilitating infrastructure, even if they do not intend to make use of it themselves. However, the very nature of MMPIs, as outlined above, renders the notion of 'allies' in these contexts problematic. To say "I am not a woman/ethnic minority myself, but I will fight for their cause" has a different psychological and interactional meaning to saying, "I eat meat but I will fight for the cause of veganism", "I drive my car everywhere but I will fight for the cause of cyclists", or "I am personally addicted to Amazon Prime delivery but I will fight for the zero-waste cause". The obvious difference is that while one could not be expected to change their gender or race group membership in order to support a minority cause, in the case of MMPI groups a supporter would perhaps be (more reasonably) expected (by themselves as much as others) to become a vegan or cyclist or to abandon their proclivity to Amazon delivery. This is not to say that non-practitioners couldn't perform acts 'sympathetic' to the causes in question, such as catering to different diets when required, driving safely around cyclists on the road or buying the occasional recycled Christmas gift for a zero-waster. However, it is questionable whether such acts are truly akin to the 'ally' status of men joining marches for gender equality or the involvement of White Americans in the Civil Rights Movement.

We acknowledge some potential between-practice nuance with regards to these dynamics. For instance, in the case of cycling it may be easier than in some other cases to be an ally of cyclists without cycling oneself, particularly if one has physical limitations that 
might preclude participation in the practice. However, in many cases, it could be suggested that it is the implausibility of taking on an 'ally' status in relation to a practice-based movement like veganism, in particular, (without becoming a vegan) that fuels the kinds of do-gooder derogation of vegans and vegetarians (Minson \& Monin 2012) so commonly observed. That is, if you don't want to join them, then derogate them! Moreover, one might also question the likely efficacy of vegan activism as practiced by meat-eaters, cycling activism as practiced by those who never cycle, or zero-waste activism as practiced by rampant consumerists. However, this remains an interesting empirical question in need of exploration.

In summary, we argue that strong ingroup identification with social groups that are defined by tightly demarcated behavioural practices may represent a barrier to conversion in MMP contexts. Moreover, we suggest that advocacy and support from non-converted outgroup members in this context is inherently problematic. Together, these points suggest that the achievement of social change may be fostered by the creation of less clearly defined inter-group boundaries in MMPI contexts. One way to do this could be through the advocation of what Kessler and colleagues (2010) term maximal, rather than minimal, moral standards. A maximal standard is one where actions in a domain are seen as aspiring to maximal standard, with any movement in that direction (e.g., reducing meat consumption, flying less) being seen as morally laudable. A minimal moral standard is one in which one must meet a clearly defined minimum threshold to be seen as moral and any violation of this renders one immoral (e.g., 'all meat is murder' or Flygskam: 'the shame of flying'). We suggest there remains some important empirical work to be done assessing the potential trade-offs between societal reach and actual level of behavioural change in response to MMPIs that advocate prohibition (minimal) versus reductionist (maximal) approaches. An alternative strategy to creating more inclusive MMP groups could be to open up opportunities 
for people to more easily change their practices without feeling they need to adopt an MMPI, a possibility that we explore below.

\section{Implications for Policy}

Our aim has been to demonstrate the utility of thinking about "pro-environmental behaviours' in terms of the MMPIs that often form around them. We argue that the notion of MMPIs provides a crucially important theoretical lens for understanding the nature of the challenges associated with any attempts to turn these from minority to majority pursuits. In this final section we consider the implications of our analysis for those seeking to promote widespread societal shifts to address sustainability challenges.

An implication of our proposed model is that MMPIs might paradoxically block societal shifts in practice due to a reluctance among non-practitioners to have to take on a practice that implies belonging to a particular minority group. This reluctance may stem from the negative stereotypes associated with the groups in question as an outcome of do-gooder derogation, or because identity-defining behaviours might seem more self-defining than people are willing for them to be in initial stages of change. Moreover, it may stem from a fear that taking on MMP group membership might imply a degree of 'no turning back' and require future consistency to which they do not feel ready to commit. Therefore, campaigns that call for people to 'Go Vegan' (even if only for a month during 'Veganuary') or to 'Become a cyclist' or 'a zero-waster household' may be problematic. Sustainable practices can be promoted in ways that are more (or less) social-identity-bound. For instance, in a recent video advertisement for online cycling magazine We Love Cycling (www.welovecycling.com) the watcher is told of the various characteristics of 'The greatest Family of all: Cyclists', with group members even being essentialised as having been 'born this way'. Such a formulation renders it notionally impossible for one to 'become a cyclist' 
even if one was ready and willing! Initiatives such as 'Meat-Free Mondays', by contrast, may avoid some of these problems.

Likewise, the provision of practice infrastructure that is strongly bound to identities is also likely to cause problems. Two recent examples on the University of Bath campus provide cases in point. The first is a response from campus services to calls for more plantbased food options on campus, in which a specifically (and exclusively) veg*an café was opened that was separate from the other food outlets. The second example relates to the provision of showering facilities on campus for those who travel to work (up the very long and steep hill) by cycling, with a requirement for those wishing to access these facilities via their university ID card to submit a request to be placed on a 'cyclists register'. Thus, potential active commuters must first register their commitment to being 'a cyclist' before trying out the behaviour. In light of our analyses above, both moves seem ill-advised. Preferable in both cases would be the provision of practice infrastructure making it easier for people to try out 'doing' a practice without having to commit to a practice-based identity. As such, showers in university buildings should simply be showers for use by whomever wishes to use them (which could include those cycling to work). Likewise, it may be more felicitous of social change to simply expand the range of meat-free options (or make vegetarian the default/majority option; as has been done at some institutions such as Utrecht University) in all existing food outlets than to establish an outlet exclusively targeting vegans and vegetarians.

There often seems a temptation amongst policy-makers to focus on supporting performance of MMP identities amongst those who are already practicing them, for example, to provide better facilities for 'the cyclists' or to provide comfortable, meat-free spaces for 'the veg*ans'. However, as Horton (2006) has pointed out, there is a strong tension between a desire to create safe spaces where the already-committed can practice green living, and the 
need for expanding the normativity of such practices. We would suggest that a focus on the former stems from an (arguably erroneous) conceptualisation of the policy challenge in terms of Wright's (2009) notion of an inter-group competition context, in which members of MMPI groups are cast as the disadvantaged and disempowered minorities. In contrast, we would encourage policy makers to instead think of the situation in terms of Wright's conversionary context, whereby the focus becomes the non-practitioners and the ways in which they might be encouraged to adopt the practices of the group. As Aldred (2012) alludes, the focus of cycling advocacy should perhaps be the psychology of 'potential cyclists', rather than the rights of existing cyclists. Moreover, recent shifts on food product labels away from 'Vegan' and 'Vegetarian' towards the more inclusive, less identity-prescriptive 'plant-based' (Sabur, 2018) suggest advertisers may have already grasped this point. To conclude, it is crucially important who feels 'included' or 'hailed' by an initiative or product. We are certainly not arguing against provision of enabling infrastructure, but rather against provision that necessitates claiming an identity in order to easily and logically gain access to it.

Individuals riding bikes instead of driving cars or replacing high-meat meals with plant-based ones is, of course, inarguably a key element of meeting sustainability goals. However, we have demonstrated how the moralised minority identities that can form around such practices may often prevent the wider adoption of more sustainable behavior and, as such, may hinder the achievement of environmental sustainability on a societal scale. Thus, we suggest the counter-intuitive policy prescription of trying to avoid, rather than promote, the formation and maintenance of strong identification with moralised minority practice identities related to sustainable conduct. Instead, approaches should look to offer easy ways for people to experiment with a practice without having to first claim (or grapple with) an associated moralised identity. 


\section{References}

Aldred, R. (2012). The role of advocacy and activism. In J. Parkin (Ed.) Cycling and sustainability (pp. 83-108). London: Emerald Group Publishing. doi:10.1108/S204499410000001019

Aldred, R. (2013). Incompetent or too competent? Negotiating everyday cycling identities in a motor dominated society. Mobilities, 8(2), 252-271. doi:10.1080/17450101.2012.696342

Bliuc, A. M., McGarty, C., Thomas, E. F., Lala, G., Berndsen, M., \& Misajon, R. (2015). Public division about climate change rooted in conflicting socio-political identities. Nature Climate Change, 5, 226-229. doi:10.1038/NCLIMATE2507

Bolderdijk, J. W., Brouwer, C., \& Cornelissen, G. (2018). When do morally motivated innovators elicit inspiration instead of irritation? Frontiers in Psychology, 8, 2362. doi:10.3389/fpsyg.2017.02362

Branscombe, N. R., Schmitt, M. T., \& Harvey, R. D. (1999). Perceiving pervasive discrimination among African Americans: Implications for group identification and well-being. Journal of Personality and Social Psychology, 77, 135-149. doi:10.1037/0022-3514.77.1.135

Brundtland, G. H. (1987). Our common future. New York, NY: Oxford University Press.

Busby, M. (2019, August 15 $\left.{ }^{\text {th }}\right)$. Arron Banks jokes about Greta Thunberg and 'freak yachting accidents'. The Guardian. https://www.theguardian .com/uk-news/2019/aug/15/arronbanks-jokes-about-greta-thunberg-and-freak-yachting-accidents

Cameron, J. E. (2004). A three-factor model of social identity. Self and Identity, 3(3), 239262. doi:10.1080/13576500444000047

Cannon, M. (2019, April 12th). Clean air zones: Where will UK drivers pay for polluting? BBC News. https://www.bbc.co.uk/news/uk-47389830 
Capstick, S. B., Demski, C. C., Sposato, R., Pidgeon, N., Spence, A., Corner, A. (2015). Public perceptions of climate change in Britain following the winter 2013/2014 flooding. Understanding Risk Research Group Working Paper 15-01. Cardiff University.

Chng, S. (in press). Furthering the use of psychological theory in sustainability research and policy: The case of transportation. Journal of Social Issues.

Cihangir, S., Barreto, M., \& Ellemers, N. (2014). Men as allies against sexism: The positive effects of a suggestion of sexism by male (vs. female) sources. Sage Open, 4(2). doi:10.1177/2158244014539168

Clark, L., (2016 April 22nd). Zero-waste bloggers: The millennials who can fit a year's worth of trash in a jar. The Guardian. https://www.theguardian.com/environment/2016/apr/22/zero-waste-millennialbloggers-trash-greenhouse-gas-emissions

Coffey, H. (2019, June $\left.5^{\text {th }}\right)$. Flygskam: What is the flight-shaming environmental movement that's sweeping Europe? The Independent. https://www.independent.co.uk/travel/news-and-advice/flygskam-anti-flying-flightshaming-sweden-greta-thornberg-environment-air-travel-train-brag-a8945196.html

Coulthard, D. W. (2009). Catching gender-identity production in flight: Making the commonplace visible. Journal of Research Practice, 5(2), Article M5. http://jrp.icaap.org/index.php/jrp/article/viewArticle/177/180

Cramwinckel, F. M., van Dijk, E., Scheepers, D., \& van den Bos, K. (2013). The threat of moral refusers for one's self-concept and the protective function of physical cleansing. Journal of Experimental Social Psychology, 49(6), 1049-1058. doi:10.1016/j.jesp.2013.07.009 
Dennings, K. (in press). Waste reduction: The forgotten R and how it impacts happiness and well-being. Journal of Social Issues.

Department for Transport (2017). Cycling and walking investment strategy.

https://www.gov.uk/government/publications/cycling-and-walking-investmentstrategy

Dreyer, S., Kurz, T., Prosser, A., Abrash Walton, A., Dennings, K., McNeill, I, Saber, D. \& Swim, J. (in press). Towards a Psychology of the Food-Energy-Water Nexus: Costs and Opportunities. Journal of Social Issues.

Drury, B. J., \& Kaiser, C. R. (2014). Allies against sexism: The role of men in confronting sexism. Journal of Social Issues, 70, 637-652. doi:10.1111/JOSI.12083

Dunlap, R. E., \& Mertig, A. G. (Eds.). (2013). American environmentalism: The U.S. environmental movement, 1970-1990. New York, NY: Routledge. doi:10.4324/9781315799193

Ellemers, N., Van Knippenberg, A., \& Wilke, H. (1990). The influence of permeability of group boundaries and stability of group status on strategies of individual mobility and social change. British Journal of Social Psychology, 29, 233-246. doi:10.1111/j.20448309.1990.tb00902.x

Fruhen, L. S., \& Flin, R. (2015). Car driver attitudes, perceptions of social norms and aggressive driving behaviour towards cyclists. Accident Analysis \& Prevention, 83, 162-170. doi:10.1016/j.aap.2015.07.003

Ginn, J. \& Lickel, B. (in press). Motivated processing of meat reduction as a climate change mitigation strategy. Journal of Social Issues.

Greenebaum, J. B. (2012). Managing impressions: "Face-saving" strategies of vegetarians and vegans. Humanity \& Society, 36, 309-325. doi:10.1177/0160597612458898 
Hoekstra, A. T. G., Twisk, D. A. M., \& Hagenzieker, M. P. (2018). Do road user roles serve as social identities? Differences between self-described cyclists and car drivers. Transportation Research Part F: Traffic Psychology and Behaviour, 59, 365377. doi:10.1016/j.trf.2018.09.006

Horton, D. (2006). Demonstrating environmental citizenship? A study of everyday life among green activists. In A. Dobson \& D. Bell (Eds.), Environmental citizenship (pp. 127-150). Cambridge, MA: MIT Press.

Jetten, J., Branscombe, N. R., Schmitt, M. T., \& Spears, R. (2001). Rebels with a cause: Group identification as a response to perceived discrimination from the mainstream. Personality and Social Psychology Bulletin, 27, 1204-1213. doi:10.1177/0146167201279012

Kessler, T., Neumann, J., Mummendey, A., Berthold, A., Schubert, T., \& Waldzus, S. (2010). How do we assign punishment? The impact of minimal and maximal standards on the evaluation of deviants. Personality and Social Psychology Bulletin, 36, 1213-1224. doi:10.1177/0146167210380603

Lorenzen, J. A. (2018). Social network challenges to reducing consumption: The problem of gift giving. Symbolic Interaction, 41, 247-266. doi:10.1002/symb.312

MacInnis, C. C., \& Hodson, G. (2017). It ain’t easy eating greens: Evidence of bias toward vegetarians and vegans from both source and target. Group Processes \& Intergroup Relations, 20, 721-744. doi:10.1177/1368430215618253

McGarty, C., Bliuc, A. M., Thomas, E. F., \& Bongiorno, R. (2009). Collective action as the material expression of opinion-based group membership. Journal of Social Issues, 65 , 839-857. doi:10.1111/j.1540-4560.2009.01627.x 
Minson, J. A., \& Monin, B. (2012). Do-gooder derogation: Disparaging morally motivated minorities to defuse anticipated reproach. Social Psychological and Personality Science, 3, 200-207. doi:10.1177/1948550611415695

Monin, B., Sawyer, P. J., \& Marquez, M. J. (2008). The rejection of moral rebels: Resenting those who do the right thing. Journal of Personality and Social Psychology, 95, 7693. doi:10.1037/0022-3514.95.1.76

Prati, G., Puchades, V. M., \& Pietrantoni, L. (2017). Cyclists as a minority group? Transportation Research Part F: Traffic psychology and behaviour, 47, 3441. doi:10.1016/j.trf.2017.04.008

Romo, L. \& Donovan-Kicken, E. (2012) “Actually, I Don't Eat Meat”: A multiple-goals perspective of communication about vegetarianism. Communication Studies, 63, 405420. doi:10.1080/10510974.2011.623752

Rosenfeld, D. L., \& Burrow, A. L. (2017). The unified model of vegetarian identity: A conceptual framework for understanding plant-based food choices. Appetite, 112, 7895. doi:10.1016/j.appet.2017.01.017

Saber, D. \& Silka, L. (in press). Sustainable consumption: The need for interdisciplinary approaches if the waste problem is to be understood and addressed.

Sabur, R. (2018, August $\left.25^{\text {th }}\right)$. Vegan a dirty word, say 'plant-based' firms. Sat $25^{\text {th }}$ August, Daily Telegraph, p.6.

Smithson, M. \& Verkuilen, J. (2006). Fuzzy set theory: Applications in the social sciences. London, UK: Sage. doi:10.1016/0165-0114(88)90002-4

Subašić, E., Hardacre, S., Elton, B., Branscombe, N. R., Ryan, M. K., \& Reynolds, K. J. (2018). "We for she": Mobilising men and women to act in solidarity for gender equality. Group Processes \& Intergroup Relations, 21, 707-724.

doi:10.1177/1368430218763272 
Swann, W. B., Jr. (2012). Self-verification theory. In P. A. M. Van Lange, A. W. Kruglanski, \& E. T. Higgins (Eds.), Handbook of theories of social psychology (p. 23-42). Sage Publications. doi:10.4135/9781446249222.n27

Tajfel, H. (1978). Interindividual behaviour and intergroup behaviour. In H. Tajfel (Ed.), Differentiation between groups: Studies in the social psychology of intergroup relations (pp. 27-60). London, UK: Academic Press.

Turner, J. C., Hogg, M. A., Oakes, P. J., Reicher, S. D., \& Wetherell, M. S. (1987). Rediscovering the social group: A self-categorization theory. Cambridge, MA: Basil Blackwell.

Twine, R. (2014). Vegan killjoys at the table: Contesting happiness and negotiating relationships with food practices. Societies, 4, 623-639. doi:10.3390/soc4040623

van Zomeren, M., Postmes, T., \& Spears, R. (2008). Toward an integrative social identity model of collective action: A quantitative research synthesis of three sociopsychological perspectives. Psychological Bulletin, 134, 504-535. doi:10.1037/00332909.134.4.504

Wellesley, L., Happer, C., \& Froggatt, A. (2015). Changing climate, changing diets: pathways to lower meat consumption. Royal Institute of International Affairs. https://www.chathamhouse.org/sites/default/files/publications/research/CHHJ3820\%2 0Diet\%20and\%20climate\%20change\%2018.11.15 WEB NEW.pdf

West-Knights (2019, October $\left.8^{\text {th }}\right)$. Why the flight-shaming movement sweeping Europe won't take off in the UK. New Statesman. https://www.newstatesman.com/politics/environment/2019/10/why-flight-shamingmovement-sweeping-europe-won-t-take-uk

Wright, S. C. (2009). The next generation of collective action research. Journal of Social Issues, 65, 859-879. doi:10.1111/j.1540-4560.2009.01628.x 


\section{Author Biographies}

Tim Kurz is Senior Lecturer in Psychology at the University of Bath (UK). His research focuses on the social psychological dimensions of attempts to foster more environmentally sustainable societies, with a particular focus on the role of morality and social interaction in processes of social change.

Annayah Prosser is currently pursuing a $\mathrm{PhD}$ in environmental identity at the University of Bath. With a background in moral psychology, she has previously conducted work at Yale University and the University of Oxford exploring 'exceptional altruists', perceptions of morality in everyday life, and transformative prosocial experiences.

Anna Rabinovich is Senior Lecturer in Psychology at the University of Exeter, UK. Her research explores group processes, sustainable attitude and behaviour change, social influence, understanding and perception of science, and communication. Her recent work focuses on sustainable land management practice change and related group dynamics in international development contexts.

Saffron O'Neill is Associate Professor in Geography at the University of Exeter. Her research explores the social science dimensions of climate variability and change, particularly in terms of communication and public engagement. She is interested in the diverse ways in which people experience climate change in their everyday lives. 